\title{
Transoral intraarticular cage distraction and C-JAWS fixation for revision of basilar invagination with irreducible atlantoaxial dislocation
}

Xiaobao Zou ${ }^{1,2+}$, Binbin Wang ${ }^{2 \dagger}$, Haozhi Yang ${ }^{2 \dagger}$, Su Ge${ }^{2}$, Bieping Ouyang ${ }^{1,2}$, Yuyue Chen ${ }^{2}$, Ling Ni², Shuang Zhang ${ }^{2}$, Hong $\mathrm{Xia}^{2}$ and Xiangyang $\mathrm{Ma}^{1,2^{*}}$

\begin{abstract}
Background: The revision surgery of basilar invagination (BI) with irreducible atlantoaxial dislocation (IAAD) after a previous occipitocervical fusion (OCF) is challenging. Transoral revision surgery has more advantages than a combined anterior and posterior approach in addressing this pathology. The C-JAWS is a cervical compressive staple that has been used in the lower cervical spine with many advantages. Up to now, there is no report on the application of C-JAWS in the atlantoaxial joint. We therefore present this report to investigate the clinical outcomes of transoral intraarticular cage distraction and C-JAWS fixation for revision of BI with IAAD.
\end{abstract}

Methods: From June 2011 to June 2015, 9 patients with BI and IAAD were revised by this technique after previous posterior OCF in our department. Plain cervical radiographs, computed tomographic scans and magnetic resonance imaging were obtained pre- and postoperatively to assess the degree of atlantoaxial dislocation and compression of the cervical cord. The Japanese Orthopedic Association (JOA) score was used to evaluate the neurological function.

Results: The revision surgeries were successfully performed in all patients. The average follow-up duration was $18.9 \pm 7.3$ months (range 9-30 months). The postoperative atlas-dens interval (ADI), cervicomedullary angle (CMA), distance between the top of the odontoid process and the Chamberlain line $(\mathrm{CL})$ and JOA score were significantly improved in all patients $(P<0.05)$. Bony fusion was achieved after 3-9 months in all cases. No patients developed recurrent atlantoaxial instability.

Conclusions: Transoral revision surgery by intraarticular cage distraction and C-JAWS fixation could provide a satisfactory outcome for BI with IAAD after a previous unsuccessful posterior operation.

Keywords: Basilar invagination, Irreducible atlantoaxial dislocation, Transoral approach, Revision surgery

\footnotetext{
* Correspondence: maxy1001@126.com

${ }^{+}$Xiaobao Zou, Binbin Wang and Haozhi Yang contributed equally and should be regarded as co-first authors.

${ }^{1}$ The First School of Clinical Medicine, Southern Medical University, No.1838 North of Guangzhou Road, Guangzhou 510515, People's Republic of China ${ }^{2}$ Department of Orthopedics, General Hospital of Southern Theatre Command of PLA, No.111 Liuhua Road, Guangzhou 510010, People's Republic of China
}

C C The Author(s). 2020 Open Access This article is licensed under a Creative Commons Attribution 4.0 International License, which permits use, sharing, adaptation, distribution and reproduction in any medium or format, as long as you give appropriate credit to the original author(s) and the source, provide a link to the Creative Commons licence, and indicate if changes were made. The images or other third party material in this article are included in the article's Creative Commons licence, unless indicated otherwise in a credit line to the material. If material is not included in the article's Creative Commons licence and your intended use is not permitted by statutory regulation or exceeds the permitted use, you will need to obtain permission directly from the copyright holder. To view a copy of this licence, visit http://creativecommons.org/licenses/by/4.0/. The Creative Commons Public Domain Dedication waiver (http://creativecommons.org/publicdomain/zero/1.0/) applies to the data made available in this article, unless otherwise stated in a credit line to the data. 


\section{Background}

Basilar invagination (BI) with atlantoaxial dislocation (AAD) usually causes severe neurological impairment because of the prolapse of the odontoid process into the foramen magnum and ventral compression of the cervical cord [1, 2]. Spinal cord decompression is the key for the improvement of neurological symptoms. Reduction of atlantoaxial joint, descent of the dens, fixation and fusion were common treatment for BI with AAD. Because of more technical difficulty of anterior approach, in clinical practice, a posterior-only occipitocervical fusion (OCF) procedure is frequently used to address BI with AAD regardless of the reducibility $[3,4]$. Once a satisfactory reduction was failed after OCF, a subsequent revision surgery, which is usually requisite for the residual compression of the spinal cord, will be more difficult to perform because the posterior structure of the craniocervical level has been destroyed in previous OCF procedure $[5,6]$. In addition, the contracture of the anterior muscles, ligaments, and capsules of atlantoaxial joint, and the formation of scar and osteophytes cause irreversible AAD, that makes reduction difficult. Transoral revision surgery has more advantages for such cases, but the familiar fixation device, like transoral atlantoaxial reduction plate (TARP), has a larger profile, that make the operation inconvenient and lead to more implants related complications $[2,5]$. It has been reported that $\mathrm{C}$ JAWS, a cervical compressive staple, can reduce the postoperative complications linked to the use of plates in anterior cervical discectomy and fusion (ACDF) due to its smaller profile $[7,8]$. Until now, no reports on the use of C-JAWS for atlantoaxial fixation has been published.

In this study, a novel revision technique of transoral intraarticular cage distraction and C-JAWS fixation was performed in 9 cases of $\mathrm{BI}$ with irreducible atlantoaxial dislocation (IAAD) after a previous failed posterior OCF, and clinical data were retrospectively analyzed to evaluate the efficacy of this technique.

\section{Methods}

\section{Patients}

From June 2011 to June 2015, a total of 9 patients (4 men and 5 women, mean age 43 yrs., range 18-67) with BI with IAAD, who underwent a previous OCF but achieved unsatisfactory results, were treated by revision surgery through transoral intraarticular cage distraction and C-JAWS fixation in our department. Of nine cases, three patients with worsening of symptoms, and 6 with unchanged symptoms. The average interval between the first OCF and revision surgery was $84.7 \pm 60.1$ months (range 18-180 months) (see Table 1 for detailed information from the cases). The clinical presentations of the 9 subjects admitted to our hospital were as follows: occipital or neck pain $(7 / 9,77.8 \%)$, extremity numbness $(8 / 9,100 \%)$, extremity weakness $(7 / 9,88.9 \%)$, unsteady gait $(3 / 9,33.3 \%)$, and hemiparalysis $(2 / 9,22.2 \%)$ (Table 2).

\section{Preoperative examinations}

Before the revision surgery, cervical plain radiographs, low-dose biphasic computed tomography (CT) [9] scans and magnetic resonance imaging (MRI) were performed. All patients were found with $\mathrm{BI}$ and $\mathrm{AAD}$ on cervical radiographs and CT scans. There were 4 patients with C2-C3 fusion and Klippel-Feil syndrome (KFS), 8 cases with atlas assimilation and 3 subjects with Chiari malformation. Bony graft nununion was found on CT scans in all patients after first OCF. MRI showed obvious ventral spinal cord compression of the cervical cord in all of the cases. The average JOA score (17-point system) was $9.7 \pm 2.2$.

\section{Surgical procedure}

For all 9 of the cases, posterior operations were performed to remove the previous implants of OCF before transoral revision surgeries. Posterior fossa decompression was additionally performed in 3 cases with Chiari malformation. All procedures were performed in one stage.

Preoperative preparations: An oral examination and dental cleaning were performed before surgery. Oral cleaning with $0.02 \%$ vinegar chlorhexidine was performed 3-6 times per day for 3 days before surgery. Broad-spectrum antibiotics were administered intravenously $30 \mathrm{~min}$ before surgery.

Surgical techniques: Under general anaesthesia with nasotracheal intubation, the patient was placed in prone position with skull traction of $4-12 \mathrm{~kg}$. After posterior median longitudinal incising and stripping, the previous internal fixation was removed. Subsequently, the patient was changed to supine position with the same weight skull traction. After conventional oral cleaning and disinfection, a longitudinal incision sized $3-4 \mathrm{~cm}$ was made in the median posterior pharyngeal wall and the anterior structure of the $\mathrm{C} 1-\mathrm{C} 2$ was exposed after separating the mucosa and muscle. Then, the anterior scar tissue and hyperplastic callus between the odontoid and anterior arch of $\mathrm{C} 1$ were resected without removal of the odontoid. After the capsule of bilateral lateral mass joints was incised, the intraarticular adherent tissues and articular cartilage were removed with a curette and grinding drill. The bilateral lateral masses were then levered in the posterosuperior and anteroinferior directions, respectively, to completely loosen the atlantoaxial joint. Then, two appropriate intraarticular cages (Wego, Shangdong, China) filled with autologous iliac bone were put into the bilateral lateral mass joints for distraction and bony 
Table 1 Demographic and clinical data of the 9 patients

\begin{tabular}{|c|c|c|c|c|c|c|}
\hline Case & Age (year)/Sex & Anomalies in radiology & Previous surgery & $\begin{array}{l}\text { Duration between the previous } \\
\text { urgery and the revision (month) }\end{array}$ & Revision cause & Revision surgery \\
\hline 1 & $59 / F$ & $\mathrm{BI}, \mathrm{IAAD}, \mathrm{AA}$ & OCF $(C 0-1)$ & 120 & IAAD with VSCC & PRI and TARF \\
\hline 2 & $41 / \mathrm{M}$ & $\mathrm{BI}, \mathrm{IAAD}, \mathrm{AA}, \mathrm{KFS}$, Chiari & OCF (CO-2) & 36 & IAAD with VSCC & PRI, PFD and TARF \\
\hline 3 & $57 / M$ & $B I, I A A D, A A$ & OCF (CO-3) & 180 & IAAD with VSCC & PRI and TARF \\
\hline 4 & $35 / F$ & $\mathrm{BI}, \mathrm{IAAD}, \mathrm{AA}, \mathrm{KFS}$ & OCF (CO-2) & 65 & IAAD with VSCC & PRI and TARF \\
\hline 5 & $67 / F$ & $\mathrm{BI}, \mathrm{AAAD}, \mathrm{AA}$, Chiari & OCF (CO-4) & 47 & IAAD with VSCC & PRI, PFD and TARF \\
\hline 6 & $27 / M$ & $\mathrm{BI}, \mathrm{IAAD}, \mathrm{AA}, \mathrm{KFS}$, Chiari & OCF (CO-2) & 132 & IAAD with VSCC & PRI, PFD and TARF \\
\hline 7 & $36 / F$ & $B I, I A A D, A A$ & OCF (CO-2) & 18 & IAAD with VSCC & PRI and TARF \\
\hline 8 & $45 / F$ & $B I, I A A D$ & OCF (CO-3) & 144 & IAAD with VSCC & PRI and TARF \\
\hline 9 & 18/M & $\mathrm{BI}, \mathrm{IAAD}, \mathrm{AA}, \mathrm{KFS}$, Chiari & OCF (CO-1) & 20 & IAAD with VSCC & PRI and TARF \\
\hline
\end{tabular}

BI basilar invagination; IAAD irreducible atlantoaxial dislocation; $A A$ atlas assimilation; KFS Klippel-Feil syndrome; Chiari Chiari malformation; OCF occipitocervical fusion; PRI posterior removal of instrument; PFD posterior fossa decompression; VSCC ventral spinal cord compression; TARF transoral atlantoaxial reduction and fixation

fusion (Fig. 1a). After reduction of the atlantoaxial joint was identified by intraoperative radiograph (Fig. 1b), holes were drilled at the midpoint of the lateral mass of $\mathrm{C} 1$ and the vertebral body of $\mathrm{C} 2$. The bilateral distances between the holes of $\mathrm{C} 1$ and $\mathrm{C} 2$ were measured and two appropriate-sized cervical compressive staples (named C-JAWS, Medicrea, Lyon, France) were chosen accordingly. Then, the C-JAWS was inserted into the desired position through preparative holes by slight knock. The bilateral arms of staples were then distracted to provide controlled compression on the joints to stabilize $\mathrm{C} 1-\mathrm{C} 2$ (Fig. 2). After a satisfactory reduction of the atlantoaxial joint and the position of C-JAWS was further confirmed by intraoperative radiograph (Fig. 1c), the muscular and mucosal were sutured in layers.

\section{Postoperative management and follow-up}

The nasal trachea cannula was removed in $24-48 \mathrm{~h}$ postoperatively, and the nasogastric tube was removed on day 7 postoperatively. Ultrasonic nebulisation and $0.02 \%$ chlorhexidine acetate gargling were performed 3-6 times per day for 7 days. Broad-spectrum antibiotics were administered intravenously for 3 days. The X-ray, CT scan and MRI scan were performed postoperatively. The atlas-dens interval (ADI), the cervicomedullary angle (CMA), and the distance between the top of the odontoid process and the Chamberlain line $(\mathrm{CL})$ were measured. The patients' neurological status was assessed using the JOA scoring system. Bony fusion was confirmed by bony bridge formation on CT scan. All cases were required to wear a rigid cervical collar for 3 months after operation. All patients were followed up at 3, 6, 9 and 12 months and then once per year.

\section{Statistical analysis}

SPSS 21.0 software (IBM, Armonk, NY, USA) was used for the statistical analysis. Measurement data were expressed as mean and standard deviation. ADI, CMA, $\mathrm{CL}$ and JOA scores before and after surgery were compared using paired-sample $t$ test, and $P$ value $<0.05$ was considered statistically significant difference.

\section{Results}

All the patients underwent transoral revision surgeries successfully after removal of the posterior internal fixation (Fig. 3). The average operative time was 251.1.9 \pm 76.4 min (range 180-400 min), with average intraoperative blood loss of $170.6 \pm 55.7 \mathrm{ml}$ (range $90-250 \mathrm{ml}$ ). No spinal cord, vascular or dura mater injuries occurred during the operation. All patients obtained satisfactory reduction, good position of implants, decompression of spinal cord, and improvement of neurological function postoperatively. The average follow-up time was $18.9 \pm$ 7.3 months (range 9-30 months). Clinical symptoms

Table 2 Clinical symptoms

\begin{tabular}{lll}
\hline Symptoms & Preoperative no. (\%) & Postoperative improvement no. (\%) \\
\hline Occipital or neck pain & $7(77.8 \%)$ & $6(85.7 \%)$ \\
Extremity numbness & $8(88.9 \%)$ & $6(75.0 \%)$ \\
Extremity weakness & $7(77.8 \%)$ & $7(100 \%)$ \\
Unsteady gait & $3(33.3 \%)$ & $3(100 \%)$ \\
Hemiparalysis & $2(22.2 \%)$ & $2(100 \%)$ \\
\hline
\end{tabular}

Each patient may have one or more symptoms 


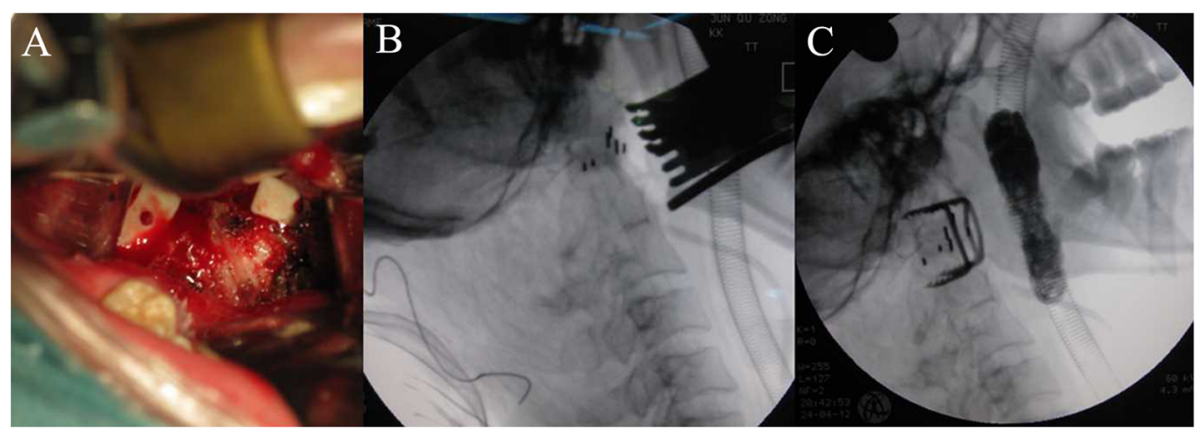

Fig. 1 Intraoperative procedures. a Photograph after the placement of bilateral intraarticular cages. $\mathbf{b}$ Intraoperative X-ray after the implantation of bilateral intraarticular cages showed satisfactory atlantoaxial reduction. C. Intraoperative X-ray after the implantation of C-JAWS showed well position of devices

were relieved in all patients after revision surgery (Table 2). Significant improvements in ADI, CMA, CL and JOA were found at the 6-month follow-up visit $(P<0.05)$ (Table 3). All the cases obtained bony fusion in 3-9 months after the revision (Table 3). No complications occurred during the follow-up.

\section{Discussion}

$\mathrm{BI}$, a relatively common malformation of the craniocervical junction, usually results in spinal cord and medulla compression if accompanied by AAD, which can cause severe neurological impairment and even sudden death [1-5]. It is usually diagnosed by cervical X-ray, CT and
MRI. The osseous variation of the craniocervical junction can be revealed by X-ray and CT scan, and the spinal cord compression can be evaluated by MRI [10]. Diffusion tensor imaging can also be performed to identify the nature of the lesion if an unknown lesion is found in the vertebrae [11]. A surgical therapy is often necessary for this disorder to obtain symptoms alleviation and spinal cord decompression. It is generally believed that surgical approaches for such patients depend mainly on the reducibility of $\mathrm{BI}$ and $\mathrm{AAD}[12,13]$. If the $\mathrm{BI}$ and $\mathrm{AAD}$ can be reduced after axial cervical traction in hyperextended position, a posterior-only approach is indicated to achieve reduction, decompression, fixation

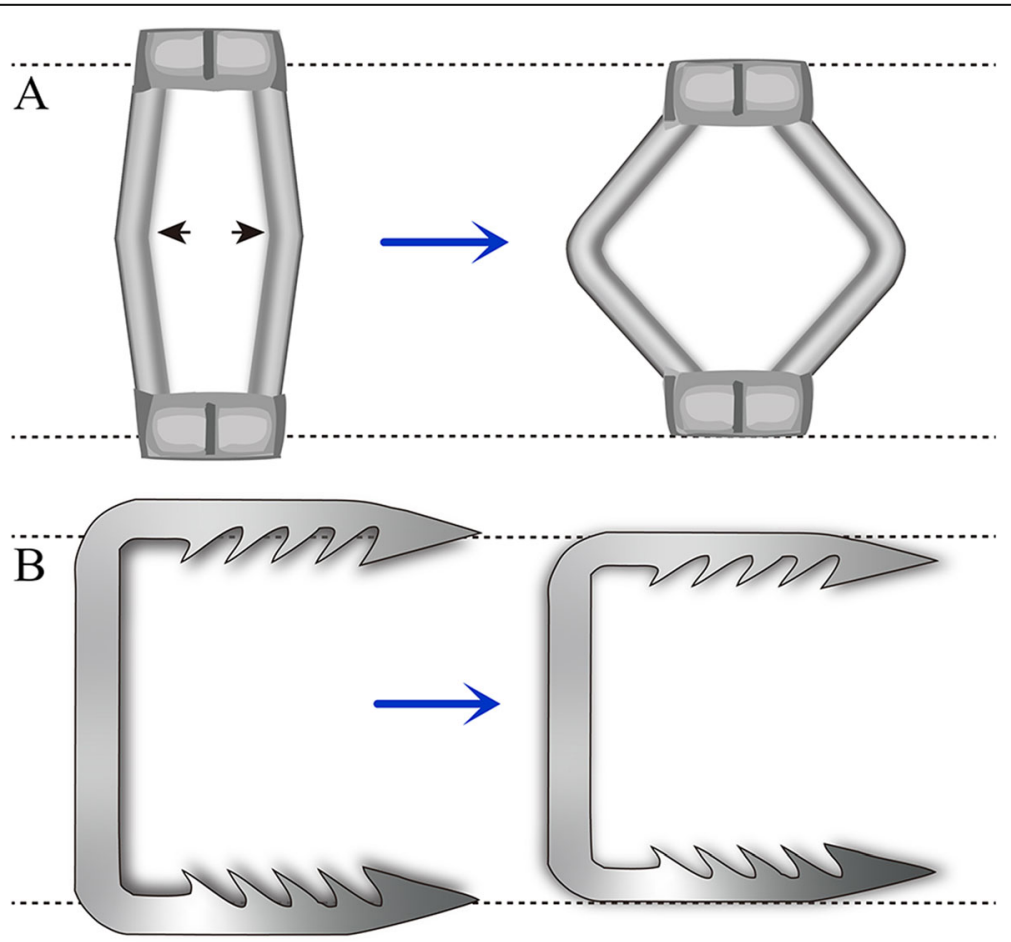

Fig. 2 Operating mode of the C-JAWS. a On the frontal views, the bilateral arms of holder were distracted to shorten the distance between the top and bottom rivets to control compression. $\mathbf{b}$ The corresponding change of holder on lateral views 


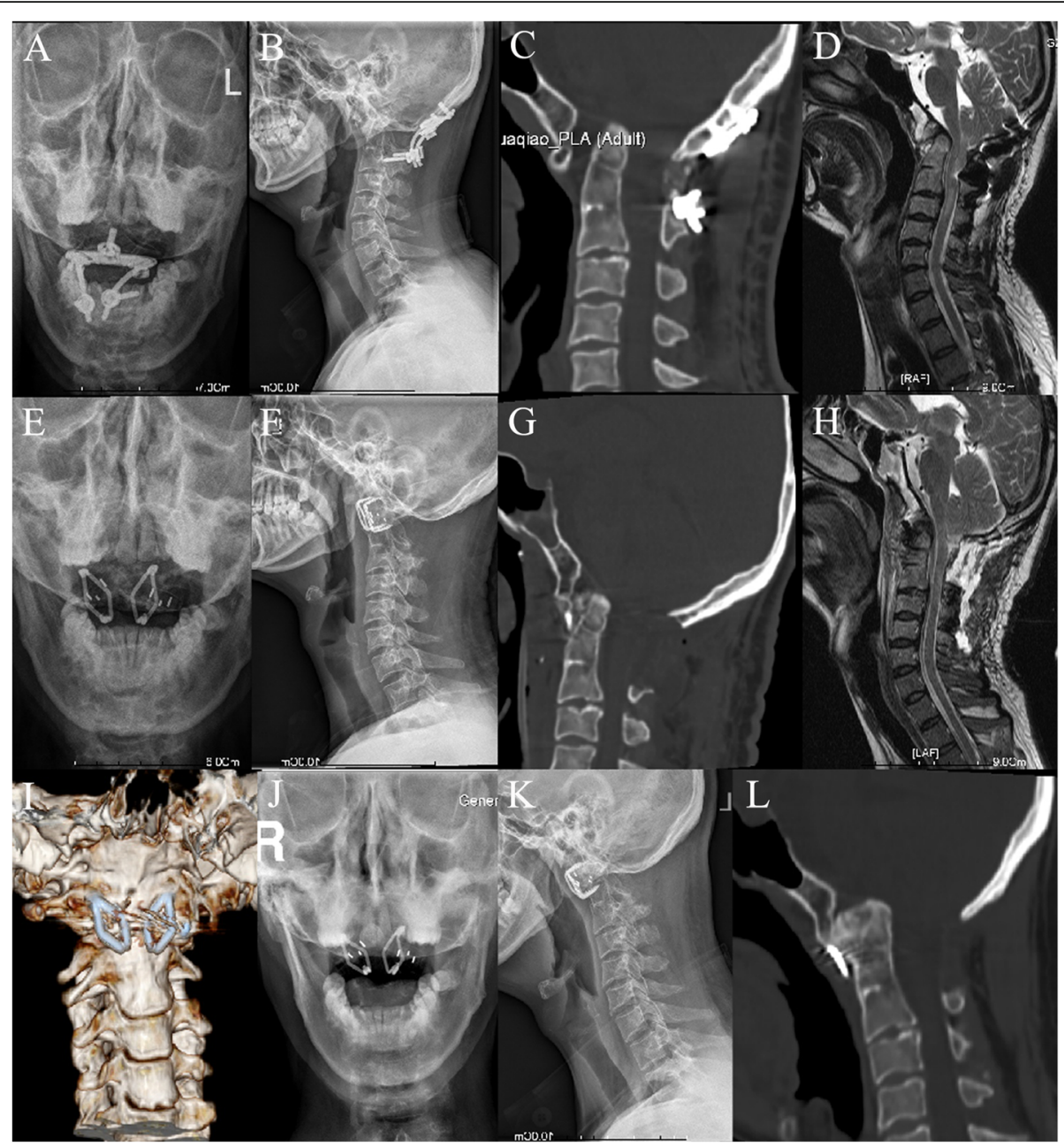

Fig. 3 A 41-year-old man was diagnosed with BI with IAAD after a failed posterior OCF, and revised by transoral intraarticular cage distraction and C-JAWS fixation. a-c Images of cervical X-rays and CT scan before revision surgery showed evidence of BI with IAAD. $\mathbf{d}$ Preoperative Sagittal MRI showed compression of the cervicomedullary junction. e-g Postoperative cervical X-rays and CT scan performed at 1 week after revision surgery showed satisfactory reduction and fixation. $\mathbf{h}$ Postoperative sagittal MRI showed a desirable decompression of the cervicomedullary junction. i Postoperative three-dimensional reconstruction showed location of C-JAWS. j-I Cervical X-rays and CT scan at 6-month follow-up showed a solid bone fusion without loss of reduction

and fusion $[3,14,15]$; If the $\mathrm{BI}$ or $\mathrm{AAD}$ cannot be reduced by cervical traction, a transoral anterior release and posterior reduction, decompression, fixation and fusion is often necessary $[4,16-18]$. But, the high risks of catastrophic complications and technique demanding of anterior procedure make the posterior-only approach preferred for BI with IAAD in clinical practice. However, the decompression effect for a posterior-only procedure may be less desirable due to unsuccessful reduction. Subsequently, a revision surgery was required to promote neurologic recovery. If patients had achieved bony fusion after previous operations, transoral odontoidectomy could be used for decompression; If patients had not achieved bony fusion, successful reduction should be considered in revision surgery [5].
Routinely, a series of procedures including posterior removal of internal fixation, transoral anterior release and posterior fixation are required to achieve ideal reduction and decompression for cases who have already undergone a posterior OCF without bony fusion, if a posterior fixation is to be again adopted in revision surgery, which may cause tremendous trauma to patients. In order to judge the degree of the release more accurately and distract the atlantoaxial joint, the removal of posterior instruments should be performed before transoral anterior release. However, the change of position after transoral anterior release, which leads to an extremely unstability of atlantoaxial joint during operation, can also cause unexpected spinal injury [5]. Furthermore, the screw placement is difficult because the 
Table 3 Pre- and Postoperative data of the 9 patients

\begin{tabular}{|c|c|c|c|c|c|c|c|c|c|c|c|}
\hline Case & $\begin{array}{l}\text { JOA } \\
\text { (preop) }\end{array}$ & $\begin{array}{l}\text { JOA } \\
\text { (postop) }\end{array}$ & $\begin{array}{l}\text { ADI } \\
\text { (preop) }\end{array}$ & $\begin{array}{l}\text { ADI } \\
\text { (postop) }\end{array}$ & $\begin{array}{l}\text { CMA } \\
\text { (preop) }\end{array}$ & $\begin{array}{l}\text { CMA } \\
\text { (postop) }\end{array}$ & $\begin{array}{l}\mathrm{CL} \\
\text { (preop) }\end{array}$ & $\begin{array}{l}\mathrm{CL} \\
\text { (postop) }\end{array}$ & $\begin{array}{l}\text { Bone fusion } \\
\text { confirmed (month) }\end{array}$ & $\begin{array}{l}\text { Follow-up } \\
\text { (month) }\end{array}$ & Complication \\
\hline 1 & 12 & 16 & 9.6 & 1.3 & 136.5 & 160.4 & 8.5 & 5.1 & 6 & 24 & No \\
\hline 2 & 10 & 15 & 8.3 & 1.8 & 143.5 & 162.6 & - & - & 3 & 12 & No \\
\hline 3 & 6 & 11 & 10.3 & 3.0 & 98.5 & 153.2 & 14.5 & 3.8 & 3 & 20 & No \\
\hline 4 & 8 & 13 & 9.8 & 0 & 112.7 & 148.1 & 10.7 & 2.9 & 9 & 30 & No \\
\hline 5 & 11 & 16 & 6.9 & 0 & 125.2 & 165.0 & - & - & 6 & 27 & No \\
\hline 6 & 8 & 12 & 8.5 & 1.5 & 105.1 & 158.4 & - & - & 6 & 9 & No \\
\hline 7 & 10 & 15 & 8.3 & 0 & 120.8 & 140.8 & 7.5 & -0.5 & 3 & 12 & No \\
\hline 8 & 13 & 17 & 7.1 & 0.6 & 133.8 & 170.1 & 15.6 & 3.0 & 9 & 21 & No \\
\hline 9 & 9 & 13 & 8.7 & 1.0 & 110.3 & 139.2 & 12.7 & 0 & 3 & 15 & No \\
\hline $\begin{array}{l}M \pm \\
S D\end{array}$ & $9.7 \pm 2.2$ & $14.2 \pm 2.0$ & $8.6 \pm 1.2$ & $1.0 \pm 1.0$ & $\begin{array}{l}120.7 \pm \\
15.3\end{array}$ & $\begin{array}{l}155.3 \pm \\
10.8\end{array}$ & $\begin{array}{l}11.6 \pm \\
3.3\end{array}$ & $2.4 \pm 2.2$ & & & \\
\hline t & -25.931 & & 21.243 & & -7.890 & & 6.334 & & & & \\
\hline$p$ & $0.000^{\mathrm{a}}$ & & $0.000^{a}$ & & $0.000^{a}$ & & $0.001^{a}$ & & & & \\
\hline
\end{tabular}

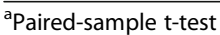

$J O A$ Japanese Orthopedic Association score; $A D I$ atlas-dens interval; $C M A$ cervicomedullary angle; $C L$ distance between the top of the odontoid process and the Chamberlain line

posterior anatomical structure of the craniocervical junction has been partly or completely destroyed after previous posterior fixation. Although the posterior screw insertion can be fulfilled by extending the segments of occipitocervical fusion as reported by Tan et al. [6] and Duan et al. [13], more cervical mobility is sacrificed.

Theoretically, the surgical related risks and injuries will significantly reduce if release, reduction, decompression, fixation and fusion can be performed through a transoral anterior-only approach after posterior removal of internal fixation. The transoral atlantoaxial reduction plate (TARP) system, designed by our institution in 2004, can achieve release, distraction, reduction, decompression, fixation and fusion in one stage with a transoral anterior-only approach $[1,5,19-22]$, that provides an effective surgical choice for the treatment of BI with IAAD accompanied by ventral spinal cord compression. Yang et al. [5] presented 30 cases with BI and IAAD after posterior fossa decompression with or without fixation, and satisfactory decompressions and improvement of neurological functions with only loss of craniocervical junction mobility were obtained through transoral anterior revision surgeries using TARP system. Wu et al. [23] reported 1 patient of os odontoideum with IAAD treated by a previous failed posterior operation undergoing a successful transoral revision surgery using TARP system. But, according to our clinical experience, to conveniently accomplish the surgical procedures in a limited oral space, especially for patients with a small mouth is difficult for the high thickness and large shape of the TARP. Additionally, the requirement of sufficient soft tissues of the pharyngeal wall to cover the plate may lead to the occurrence of postoperative dysphagia and wound dehiscence [21, 24].

The C-JAWS, a cervical compressive staple, is commonly used in ACDF. Fiere et al. [7] reported a dependable biomechanical stability of the C-JAWS in a vitro testing, and the early clinical results of 23 cases who underwent ACDF using a C-JAWS with a thickness of $1.5 \mathrm{~mm}$ showed various advantages including short incision, short operative time and lower rate of dysphagia incidences as compared to most of the cervical anterior plate. Xia et al. [8] presented 9 cases undergoing ACDF with C-JAWS and a similar conclusion was concluded.

Because the C-JAWS is much thinner and smaller than the TARP, we deem it can also reduce complications associated with internal instruments, if it is applied in transoral atlantoaxial fixation. But the C-JAWS does not have the same function of joint distraction as TARP does, so an intraarticular cage was used in revision surgery for atlantoaxial joint distraction. In this study, 9 patients presenting with severe BI with IAAD had neurological function deterioration after a posterior OCF without bony fusion, and were revised by this novel transoral revision surgery. All patients achieved satisfactory reduction and significant improvement of neurological function without postoperative complications. According to our experience, this novel technique can facilitate the operation and reduce the complications associated with internal fixation. However, the C-JAWS only has a fixed function, and does not have the same reduction mechanism as TARP.

There are several limitations in current study. First, the sample size was relatively small. As more cases are 
performed using this technique, its efficacy may be more thoroughly evaluated. In addition, the present study is retrospective in nature; future prospective studies may better control of follow-up timing intervals and may have the potential to include more standardized outcome measures.

\section{Conclusions}

Revision surgery through transoral intraarticular cage distraction and C-JAWS fixation is an effective procedure in treatment of patients with BI and IAAD after an unsuccessful posterior OCF. This technique can provide satisfactory reduction, fixation and bony fusion, and also offered a new method for transoral atlantoaxial fixation.

\section{Abbreviations}

Bl: Basilar invagination; IAAD: Irreducible atlantoaxial dislocation; AAD: Atlantoaxial dislocation; TARP: Transoral atlantoaxial reduction plate; ADI: Atlas-dens interval; CMA: Cervicomedullary angle; CL: Distance between the tip of the dens and Chamberlain line; JOA: Japanese Orthopedic Association score; Chiari: Chiari malformation; KFS: Klippel-Feil syndrome; OCF: Occipitocervical fusion; CT: Computed tomographic; MRI: Magnetic resonance imaging; $A A$ : Atlas assimilation; PRI: Posterior removal of instrument; PFD: Posterior fossa decompression; TAADF: Transoral atlantoaxial distraction and fixation; ACDF: Anterior cervical discectomy and fusion

\section{Acknowledgements}

We would like to thank Jianhua Wang, Kai Zhang, Qiang Tu for guidance of measurement of radiographic data.

\section{Authors' contributions}

MX designed the study and critically revised the manuscript. ZX carried out the statistical analyses, and drafted the manuscript. WB, YH, GS, OB, CY, NL, $\mathrm{ZS}$ were responsible for the data collection and measurement of radiographic data. $\mathrm{XH}$ checked the manuscript. All authors read and approved the final manuscript.

\section{Funding}

This work was supported by the Guangzhou Municipal Science and Technology Project (No. 201803010046); the National Natural Science Foundation of China (No. 81672232); and the Science and Technology Planning Project of Guangdong Province (No. 2015B020233013).

\section{Availability of data and materials}

The data used and analyzed during the current study are available in anonymized form from the corresponding author on reasonable request.

\section{Ethics approval and consent to participate}

This study was approved by the ethics committee of General Hospital of Southern Theatre Command of PLA and the written informed consent for participation in the study was obtained.

\section{Consent for publication}

Written informed consent was obtained from all individual participants included in the study.

\section{Competing interests}

The authors declare that they have no competing interests.

Received: 15 September 2020 Accepted: 12 November 2020 Published online: 20 November 2020

\section{References}

1. Wei G, Shi C, Wang Z, Xia H, Yin Q, Wu Z. Surgical outcome and prognostic analysis of Transoral Atlantoaxial reduction plate system for basilar invagination: a voxel-based Morphometry study. J Bone Joint Surg Am. 2016:98:1729-34.
2. Lan S, Xu J, Wu Z, Xia H, Ma X, Zhang K, Ai F, Wang J, Yin Q, Yi H, Duan M. Atlantoaxial joint distraction for the treatment of basilar invagination: clinical outcomes and radiographic evaluation. World Neurosurg. 2018;111: e135-41.

3. Salunke $P$, Karthigeyan M, Malik P. Foramen magnum decompression without bone removal: C1-C2 posterior fixation for Chiari with congenital atlantoaxial dislocation/basilar invagination. Surg Neurol Int. 2019;10:38.

4. Srivastava SK, Aggarwal RA, Nemade PS, Bhosale SK. Single-stage anterior release and posterior instrumented fusion for irreducible atlantoaxial dislocation with basilar invagination. Spine J. 2016;16:1-9.

5. Yang J, Ma X, Xia H, Wu Z, Ai F, Yin Q. Transoral anterior revision surgeries for basilar invagination with irreducible atlantoaxial dislocation after posterior decompression: a retrospective study of 30 cases. Eur Spine J. 2014;23:1099-108.

6. Tan M, Jiang X, Yi P, Yang F, Tang X, Hao Q, Zhang G. Revision surgery of irreducible atlantoaxial dislocation: a retrospective study of 16 cases. Eur Spine J. 2011;20:2187-94

7. Fiere V, Greff G, Mosnier T, Faline A. New cervical compressive staple: in vitro testing and early clinical results. J Spinal Disord Tech. 2013;26(7): 385-92.

8. Xia L, Liu MX, Zhong J, Zhu J, Dou NN, Visocchi M. Anterior cervical discectomy and fusion with a compressive staple of C-JAWS. Br J Neurosurg. 2016;30(6):649-53.

9. Elmokadem AH, Ibrahim EA, Gouda WA, Razek AA. Whole-body computed tomography using low-dose biphasic injection protocol with adaptive statistical iterative reconstruction V: assessment of dose reduction and image quality in trauma patients. J Comput Assist Tomogr. 2019;43:870-6.

10. Abdel Razek AA, Castillo M. Imaging appearance of primary bony tumors and pseudo-tumors of the spine. J Neuroradiol. 2010;37:37-50.

11. Razek AAKA, Sherif FM. Diagnostic accuracy of diffusion tensor imaging in differentiating malignant from benign compressed vertebrae. Neuroradiology. 2019;61:1291-6.

12. Liao Y, Pu L, Guo H, Mai E, Liang W, Deng Q, Xu T, Sheng J, Sheng W. Selection of surgical procedures for basilar invagination with atlantoaxia dislocation. Spine J. 2016;16:1184-93.

13. Duan W, Chou D, Jiang B, Liu Z, Zhao X, Xia Z, Jian F, Chen Z. Posterior revision surgery using an intraarticular distraction technique with cage grafting to treat atlantoaxial dislocation associated with basilar invagination. J Neurosurg Spine. 2019;05:1-9.

14. Wang HW, Yin YH, Li T, Yu XG, Qiao GY. Effects of transverse connector on reduction and fixation of atlantoaxial dislocation and basilar invagination using posterior C1-C2 screw-rod technique. Spine J. 2019; 19:1995-2002.

15. Meng Y, Chen H, Lou J, Rong X, Wang B, Deng Y, Ding C, Hong Y, Liu H. Posterior distraction reduction and occipitocervical fixation for the treatment of basilar invagination and atlantoaxial dislocation. Clin Neurol Neurosurg. 2016;140:60-7.

16. Wang Q, Mao K, Wang C, Mei W. Transoral Atlantoaxial release and posterior reduction by Occipitocervical plate fixation for the treatment of basilar invagination with irreducible Atlantoaxial dislocation. J Neurol Surg A Cent Eur Neurosurg. 2017;78:313-20.

17. Rathod TN, Marathe NA, Sathe AH, Mohanty SS, Mallepally AR. Anterior distraction and reduction with posterior stabilization for basilar invagination: a novel technique. World Neurosurg. 2020;145:19-24.

18. Laheri V, Chaudhary K, Rathod A, Bapat M. Anterior transoral atlantoaxial release and posterior instrumented fusion for irreducible congenital basilar invagination. Eur Spine J. 2015;24(12):2977-85.

19. Wei G, Wang Z, Ai F, Yin Q, Wu Z, Ma XY, Xu J, Shi C, Xia H. Treatment of basilar invagination with Klippel-Feil syndrome: Atlantoaxial joint distraction and fixation with Transoral Atlantoaxial reduction plate. Neurosurgery. 2016; 78:492-8.

20. Zhu C, Wang J, Wu Z, Ma X, Ai F, Xia H. Management of pediatric patients with irreducible atlantoaxial dislocation: transoral anterior release, reduction, and fixation. J Neurosurg Pediatr. 2019;14:1-7.

21. Yin QS, Li XS, Bai ZH, Mai XH, Xia H, Wu ZH, Ma XY, Ai FZ, Wang JH, Zhang K. An 11-Year Review of the TARP Procedure in the Treatment of Atlantoaxial Dislocation. Spine (Phila Pa 1976). 2016;41:E1151-8.

22. Xia H, Yin Q, Ai F, Ma X, Wang J, Wu Z, Zhang K, Liu J, Xu J. Treatment of basilar invagination with atlantoaxial dislocation: atlantoaxial joint distraction and fixation with transoral atlantoaxial reduction plate (TARP) without odontoidectomy. Eur Spine J. 2014;23:1648-55. 
23. Wu Z, Xu J, Wang Z, Xia H, Zhang Q, Ma X, Zhang K. Transoral approach for revision surgery of os odontoideum with atlantoaxial dislocation. Orthopedics. 2014;37(9):e851-5.

24. Yin Q, Xia H, Wu Z, Ma X, Ai F, Zhang K, Wang J, Zhang T, Bai Z, Wang Z. Surgical site infections following the Transoral approach: a review of 172 consecutive cases. Clin Spine Surg. 2016;29:E502-8.

\section{Publisher's Note}

Springer Nature remains neutral with regard to jurisdictional claims in published maps and institutional affiliations.

Ready to submit your research? Choose BMC and benefit from:

- fast, convenient online submission

- thorough peer review by experienced researchers in your field

- rapid publication on acceptance

- support for research data, including large and complex data types

- gold Open Access which fosters wider collaboration and increased citations

- maximum visibility for your research: over $100 \mathrm{M}$ website views per year

At BMC, research is always in progress.

Learn more biomedcentral.com/submissions 